\title{
Effects of Progressive Depletion of TCM1 or CYH2 mRNA on Saccharomyces cerevisiae Ribosomal Protein Accumulation
}

\author{
HONG GIL NAM ${ }^{1}$ AND HOWARD M. FRIED ${ }^{2 *}$ \\ Departments of Chemistry and Biochemistry, ${ }^{2}$ University of North Carolina, Chapel Hill, North Carolina 27514
}

Received 31 January 1986/Accepted 12 February 1986

\begin{abstract}
When present in excess, the mRNAs for Saccharomyces cerevisiae ribosomal proteins L3 and L29 are translated less efficiently, so that synthesis of these proteins remains commensurate with that of other ribosomal proteins (N. J. Pearson, H. M. Fried, and J. R. Warner, Cell 29:347-355, 1982; J. R. Warner, G. Mitra, W. F. Schwindinger, M. Studeny, and H. M. Fried, Mol. Cell. Biol. 5:1512-1521, 1985). We used a yeast strain with a conditionally transcribed derivative of the $\mathrm{L3}$ gene to deplete cells progressively of L3 mRNA. In this case translation of L3 mRNA did not become more efficient so that L3 was not maintained at a normal level. Even when there was an initial excess of L3 mRNA, interruption of its further transcription produced an immediate drop in L3 synthesis, suggesting that the translational efficiency of preexisting mRNA cannot be altered. Lack of $L 3$ synthesis afforded an opportunity to examine coordinate accumulation of other ribosomal proteins. Without L3, apparent synthesis of several 60S subunit proteins diminished, and 60S subunits did not assemble. A similar phenomenon occurred when, in a second strain, synthesis of ribosomal protein L29 was prevented. Loss of $60 \mathrm{~S}$ subunit assembly was accompanied by a destabilization of some 605 ribosomal protein mRNAs. These data suggest that synthesis of some $S$. cerevisiae ribosomal proteins may be regulated posttranscriptionally as a function of the extent to which they are assembled.
\end{abstract}

Saccharomyces cerevisiae strains growing in stable environmental circumstances accumulate each of 70 or so ribosomal proteins in a stoichiometric and coordinate fashion. This situation exists in part because most proteins appear to be present in a single copy in the ribosome and because unassembled ribosomal proteins account for little if any of the total amount of ribosomal protein (see reference 27 for a review). Besides providing a sufficient number of ribosomes for a given growth condition, the rigorous coordination of ribosomal protein accumulation prevents the waste of synthetic energy, which may be especially important as these proteins are among the more abundant in most cells. In $S$. cerevisiae, an example of non-overproduction of a ribosomal protein was found by increasing the gene number for ribosomal protein L3; despite an elevated amount of L3 mRNA, no increased synthesis of L3 was observed (23). (When possible, ribosomal proteins are designated L3, L29, etc., by the system of Kruiswijk and Planta [16]. Proteins not crossreferenced with this system are designated rp39, rp59, etc., by the system of Gorenstein and Warner [10].) More recently, this apparent translational control has been found to operate on the mRNAs for ribosomal proteins L29, rp59, and rp39 (12, 28; J. Woolford, personal communication).

While yeast cells appear to reduce translation of some ribosomal protein $\mathrm{mRNAs}$ when present in excess, it is not known how this regulation comes about, although for L3 and L29 it is known that the excess mRNA is actually in polyribosomes and is thus translated (28). For L3, an overabundance of its mRNA causes that transcript to appear in smaller polyribosomes, suggesting that translational initiation is reduced. The agent which brings about reduced translation is unknown, but by analogy with ribosome regulation in Escherichia coli (21) may be connected to the presence of more protein than can be assembled.

Previously we reported that $S$. cerevisiae strains with a partially inactivated promoter of $T C M 1$, the gene encoding

\footnotetext{
* Corresponding author.
}

ribosomal protein L3, accumulated more L3 mRNA than expected from the transcriptional activity of the altered TCMI promoter (6). We speculated that perhaps to compensate for a lower than usual amount of L3 mRNA, cells increased its translation rate, which then led to increased stability and elevated mRNA accumulation. Alternatively, since transcriptional activity was measured by fusing the promoter to the $E$. coli $\beta$-galactosidase gene, it was possible that the $\beta$-galactosidase fusions simply did not precisely reflect the activity of the altered $\mathrm{L} 3$ promoter after that promoter had been integrated into its normal genomic setting adjacent to the L3 coding sequence. Since the transcription rate is so low, we have not been able to to resolve this uncertainty by measuring mRNA synthesis directly. Nonetheless, in this report we have addressed the question of enhanced translation under conditions of reduced mRNA abundance by measuring the rate of synthesis of the L3 protein itself.

In the strain just described, the activation sequence of the L3 promoter had been replaced with one requiring an inducer for $\mathrm{L} 3$ to be transcribed. Upon removal of inducer, the transcription rate dropped to the essentially unmeasurable level indicated above, so that the L3 mRNA present before inducer withdrawal became progressively depleted. At the same time, synthesis of L3 dropped continuously at a rate identical to the disappearance of its mRNA. Thus, under these conditions and contrary to our initial speculation, yeast cells did not enhance translation of L3 mRNA. In fact, prior to inducer removal, these cells actually had two to four times more mRNA than normal because the replacement transcriptional activation sequence produced a stronger L3 promoter. Consistent with earlier gene dosage experiments (see above), L3 was not overproduced; yet upon cessation of L3 transcription there was also no lag before L3 synthesis fell. Such a lag would have been expected if the preexisting undertranslated mRNA were restored to full potential. Although we can only offer a hypothesis for this observation 
(see Discussion), it nevertheless emphasized the lack of translational compensation during mRNA depletion.

Finally, the availability of strains with conditionally expressed ribosomal protein genes also afforded an opportunity to examine the effect that reduced expression of one gene had on the coordinate accumulation of other ribosomal proteins. In bacteria, coordinate synthesis of ribosomal proteins is due in part to the organization of ribosomal protein genes into polycistronic transcription units (21), a situation which does not exist in eucaryotes. Depletion of L3, a $60 \mathrm{~S}$ protein, did not affect $40 \mathrm{~S}$ protein synthesis or accumulation of $40 \mathrm{~S}$ subunits. $60 \mathrm{~S}$ protein synthesis appeared to drop to an average of $60 \%$ of normal, but since $60 \mathrm{~S}$ subunits did not accumulate, this decline may have been an overestimate due to rapid turnover of unassembled proteins. Yet a few exceptional large subunit proteins showed apparent synthesis rates only 30 to $40 \%$ of normal. Evidence is presented that this drop was due to an actual decline in synthesis, which would be an appropriate regulatory response to limit production of proteins which cannot contribute to ribosome formation.

\section{MATERIALS AND METHODS}

Strains, media, and chemicals. $S$. cerevisiae strains pGTCM $\Delta 3^{\prime} B$ and pGCYH $\Delta 3^{\prime}$ contain conditionally expressed derivatives of ribosomal protein genes TCMI and $C Y H 2$, respectively (6). In this report we designate these two strains GTCM-B and GCYH-A. They were grown in $2 \%$ galactose containing $0.7 \%$ yeast nitrogen base (Difco Laboratories) and supplemented with $40 \mu \mathrm{g}$ of required amino acids per ml. Radiochemicals were purchased from ICN Pharmaceuticals, Inc., Irvine, Calif.

Primer extension analysis. The 5' end of L3 mRNA was mapped by hybridizing an oligodeoxyribonucleotide, complementary to codons 35 through 40 of $T C M I$, to total RNA derived from wild-type and GTCM-B cells and extending it with avian myeloblastosis virus reverse transcriptase (Life Sciences) exactly as described previously (5). The oligonucleotide was synthesized with an Applied Biosystems model 380A DNA synthesizer.

RNA quantitation. RNA was extracted, separated by size in denaturing gels, transferred to nitrocellulose, and hybridized to ${ }^{32} \mathrm{P}$-labeled M13 phage DNA probes as previously described (6). Strains GTCM-B and GCYH-A contain, in addition to a complete copy of $T C M 1$ and $C Y H 2$, respectively, a copy of $T C M I$ or $C Y H 2$ in which plasmid pBR322 has been inserted. To prevent detection of TCMI- and CYH2-pBR322 transcripts, segments of each gene containing only sequences distal to the site of plasmid insertion were cloned into M13 and used as probes.

Measurement of rate of synthesis of ribosomal proteins. The rates of synthesis of ribosomal proteins were measured essentially by the method of Gorenstein and Warner (10). Cells were grown in galactose medium at $30^{\circ} \mathrm{C}$, and at mid-log phase a 5-ml portion was pulse-labeled for $3 \mathrm{~min}$ with $0.5 \mathrm{mCi}$ of $\left[{ }^{3} \mathrm{H}\right]$ leucine $(120 \mathrm{Ci} / \mathrm{mmol})$, after which the cells were poured into ice-cold leucine $(1 \mathrm{mg} / \mathrm{ml})$, harvested, and frozen at $-80^{\circ} \mathrm{C}$. The remaining cells were harvested at room temperature by brief centrifugation and suspended in glucose medium. At 15, 30, 60, and 120 min after medium transfer, a sample of cells was pulse-labeled with $\left[{ }^{3} \mathrm{H}\right] l e u c i n e$ as before the shift. Each of the five ${ }^{3} \mathrm{H}$-labeled cell samples was mixed with an approximately equal number of radioactive counts of cells grown for two generations in galactose medium containing $5 \mu \mathrm{Ci}$ of $\left[{ }^{14} \mathrm{C}\right]$ leucine $(270 \mathrm{mCi} / \mathrm{mmol})$ per $\mathrm{ml}$. Total cell protein from each sample was extracted with $67 \%$ acetic acid, dialyzed against $1 \%$ acetic acid, lyophilized, and subjected to two-dimensional acrylamide gel electrophoresis (10). Gels were stained with $0.2 \%$ Coomassie blue, protein spots were excised and dissolved with $\mathrm{H}_{2} \mathrm{O}_{2}$, and their radioactivity was determined by scintillation counting.

In addition to $\left[{ }^{3} \mathrm{H}\right]$ leucine labeling, portions of the same cell samples were harvested and extracted with phenol to isolate RNA for blot hybridization.

Measurement of synthesis and accumulation of rRNA. Labeling of rRNA was performed as described previously (13). Cells growing in galactose and at 1 and $2 \mathrm{~h}$ after transfer to glucose medium were pulse-labeled for $5 \mathrm{~min}$ at $23^{\circ} \mathrm{C}$ with $100 \mu \mathrm{Ci}$ of $\mathrm{L}-\left[\right.$ methyl $\left.-{ }^{3} \mathrm{H}\right]$ methionine $(50 \mathrm{Ci} / \mathrm{mmol})$ per $\mathrm{ml}$. Half of the pulse-labeled culture was mixed with an equal amount of cells labeled for two generations in galactose medium containing $0.05 \mu \mathrm{Ci}$ of $\left[{ }^{14} \mathrm{C}\right]$ uracil $(50 \mathrm{mCi} / \mathrm{mmol})$ per $\mathrm{ml}$, and the cells were harvested and frozen at $-80^{\circ} \mathrm{C}$. The other half of the pulse-labeled cells were subjected to a chase by addition of unlabeled methionine to $100 \mu \mathrm{g} / \mathrm{ml}$ for $15 \mathrm{~min}$, mixed with ${ }^{14} \mathrm{C}$-labeled cells, and harvested. RNA was extracted and analyzed by electrophoresis in $2.75 \%$ polyacrylamide gels (25), which were sliced and counted in a scintillation counter.

Measurement of synthesis and accumulation of mRNA. mRNA synthesis and accumulation were quantitated by hybridizing RNA, labeled in vivo with $\left[{ }^{3} \mathrm{H}\right]$ uracil, to nylon filter disks containing immobilized single-stranded M13 phage clones of various genes. Briefly, $10 \mu \mathrm{g}$ of singlestranded DNA (prepared by the method of $J$. Griffith, personal communication) were spotted onto $0.7-\mathrm{cm}$ nylon disks (0.2 $\mu \mathrm{m}$ BNRG; Pall Corp., Glen Cove, N.Y.), blotted dry, incubated for $1 \mathrm{~h}$ at $80^{\circ} \mathrm{C}$ in vacuo, and irradiated at 254 $\mathrm{nm}$ at $32,000 \mu \mathrm{W} / \mathrm{cm}^{2}$ for $1 \mathrm{~s}$ to couple the DNA to the filters. The filters were then placed in $\mathrm{H}_{2} \mathrm{O}$ at $90^{\circ} \mathrm{C}$ for $10 \mathrm{~min}$ to remove unbound DNA and prehybridized twice for $24 \mathrm{~h}$ at $42^{\circ} \mathrm{C}$ in $50 \%$ formamide- $2 \times \mathrm{SSC}(1 \times \mathrm{SSC}$ is $0.15 \mathrm{M} \mathrm{NaCl}$ plus $0.015 \mathrm{M}$ sodium citrate) $-0.1 \mathrm{M} \mathrm{NaPO}-0.4 \%$ sodium dodecyl sulfate- $0.04 \%$ Ficoll $-0.04 \%$ polyvinylpyrollidone. The filters were then rinsed five times with $\mathrm{H}_{2} \mathrm{O}$ and placed in a small plastic bag with $0.5 \mathrm{ml}$ of prehybridization solution, to which was added ${ }^{3} \mathrm{H}$-labeled RNA. Hybridization proceeded for $50 \mathrm{~h}$ at $42^{\circ} \mathrm{C}$, after which the filters were washed 10 times in $2 \times \mathrm{SSC}-40 \%$ formamide $-0.2 \%$ sodium dodecyl sulfate at $40^{\circ} \mathrm{C}$ and twice at room temperature in $2 \times$ SSC, rinsed once in $95 \%$ ethanol, dried, and subjected to scintillation counting.

In vivo-labeled RNA was obtained by incubating cells grown to $10^{7} / \mathrm{ml}$ with $200 \mu \mathrm{Ci}$ of $\left[{ }^{3} \mathrm{H}\right]$ uracil $(50 \mathrm{Ci} / \mathrm{mmol})$ per $\mathrm{ml}$ (14). After 7 and $50 \mathrm{~min}$, portions of labeled cells were removed, added to $10 \mathrm{ml}$ of ice-cold $\mathrm{H}_{2} \mathrm{O}$, spun at 7,000 $\times \mathrm{g}$ for $2 \mathrm{~min}$, and frozen at $-70^{\circ} \mathrm{C}$. RNA was extracted and hybridized to immobilized phage clones. Approximately 25 $\mu \mathrm{g}$ of total ${ }^{3} \mathrm{H}$-labeled RNA from cells grown on glucose was hybridized per set of filters. Four times as much RNA from galactose-grown cells was used, because labeling in galactose gave RNA with a fourfold-lower specific activity.

\section{RESULTS}

Characteristics of strain with inducer-dependent $\mathrm{L3}$ gene. As described in the Introduction, we constructed an $S$. cerevisiae strain unable to transcribe the gene $T C M 1$ unless grown in the presence of the inducer galactose (6). This gene, which encodes ribosomal protein L 3 (7), was rendered galactose dependent by replacing the $T C M I$ transcriptional activation sequence with the $S$. cerevisiae $G A L 10$ activation 


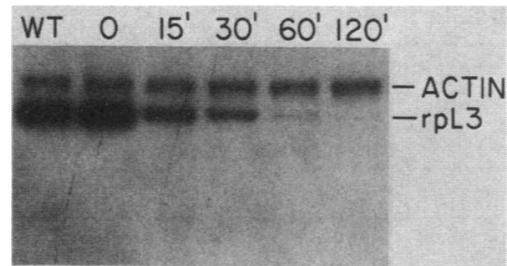

FIG. 1. Northern blot hybridization analysis of RNA extracted from strain GTCM-B. WT, RNA from wild-type cells. The remaining samples are RNA derived from GTCM-B cells grown on galactose (lane 0 ) and at the indicated times (in minutes) after transfer to glucose medium.

sequence. When propagated on galactose, the modified strain, GTCM-B, produced at least a wild-type amount of L3 mRNA (see below) and grew at a wild-type rate (6). Transfer of GTCM-B to medium lacking galactose resulted in an immediate cessation of $T C M 1$ transcription, and over the course of about $2 \mathrm{~h}$ the L3 mRNA present before the shift became progressively depleted to about $5 \%$ of normal (Fig. 1). For up to $5 \mathrm{~h}$ after shifting GTCM-B from galactose to glucose, the cells continued growing with the same doubling time as before the shift (data not shown). Incorporation of $\left[{ }^{3} \mathrm{H}\right]$ leucine into total protein dropped initially by about $45 \%$, probably the result of manipulating the cells from one medium to another, but it continued to increase after the shift (Table 1). Thus, despite continued loss of L3 mRNA, the general well-being of strain GTCM-B was not adversely affected, and we proceeded to measure the rates of synthesis of $\mathrm{L} 3$ and other ribosomal proteins during reduced L3 mRNA abundance.

Synthesis of ribosomal protein $\mathrm{L3}$ as a function of its mRNA abundance. The rate of synthesis of ribosomal proteins was determined by a 3-min $\left[{ }^{3} \mathrm{H}\right]$ leucine pulse-label of GTCM-B cells growing on galactose and at various times after transfer to glucose medium. The pulse-labeled cells were mixed with cells labeled for two generations in galactose medium containing $\left[{ }^{14} \mathrm{C}\right]$ leucine, ribosomal proteins were separated by two-dimensional polyacrylamide gel electrophoresis, and the ${ }^{3} \mathrm{H} /{ }^{14} \mathrm{C}$ ratio of each was determined by scintillation counting. When expressed as a function of the ${ }^{3} \mathrm{H} /{ }^{14} \mathrm{C}$ ratio of total protein, the value is a measure of the rate of synthesis of an individual protein (10).

The ability of cells to synthesize L3 fell in direct proportion to the disappearance of L3 mRNA (Fig. 2, Table 2). Thus, in this experiment $S$. cerevisiae cells did not elevate translation of the ever-diminishing L3 mRNA and were therefore unable to maintain a normal rate of $\mathrm{L} 3$ synthesis. Even in the initial states of mRNA depletion, when it would

TABLE 1. Incorporation of $\left[{ }^{3} \mathrm{H}\right]$ leucine by GTCM-B cells before and after a shift from galactose to glucose medium ${ }^{a}$

\begin{tabular}{cc}
\hline $\begin{array}{c}\text { Time postshift } \\
\text { (min) }\end{array}$ & $\begin{array}{c}{ }^{3} \mathrm{H} \text { incorporation } \\
\text { (cpm/107 cells) }\end{array}$ \\
\hline 0 & 95,000 \\
15 & 52,000 \\
30 & 56,700 \\
60 & 80,000 \\
120 & 477,000 \\
\hline
\end{tabular}

a Cells were pulse-labeled as described in Materials and Methods. Prior to extraction, a small sample was suspended in scintillation counting solution and radioactivity was determined. Cell number was measured by light scattering in a spectrophotometer just prior to labeling. seem biologically useful for some lag in declining L3 synthesis to occur, there was no evidence of such a phenomenon.

Confirmation of $5^{\prime}$ sequence of $L 3$ mRNA. Translational regulation and translational efficiency of specific mRNAs usually rely on nucleotide sequences which participate in the initiation step $(9,15,20,24$; S. B. Baim, Ph.D. thesis, University of Rochester, Rochester, N.Y., 1984). Since the L3 gene used in our experiment was constructed by insertion of a regulatory sequence into the $T C M I$ promoter, we wanted to be certain that the $5^{\prime}$ sequence of mRNA derived from it was identical to the wild type sequence to eliminate the possibility that lack of enhanced translation was due to a transcript with an altered nucleotide sequence. Thus, we used a primer extension assay to map the $5^{\prime}$ end of $\mathrm{L3}$ mRNA from wild-type cells and from GTCM-B cells growing on galactose. An 18-residue synthetic oligonucleotide complementary to codons 35 through 40 of TCMI was hybridized to the RNA and extended with reverse transcriptase. RNA from both sources produced a major extended product of exactly the same length, 141 nucleotides, placing the $5^{\prime}$ end of L3 mRNA 21 nucleotides upstream of the initiator methionine (Fig. 3). The identity of wild-type and GTCM-B mRNA 5 ' ends shows that lack of enhanced translation was not a consequence of an altered mRNA sequence.

Synthesis and accumulation of L3 mRNA in inducerdependent strain. It was possible that the failure of cells to maintain, at least for a while, normal synthesis of L3 was because insertion of the GALIO activation sequence upstream of $T C M I$ yielded a promoter which produced less L3 mRNA than the wild type. If so, L3 mRNA might have already been translated at a higher than normal rate and so there would not have been any additional capacity to compensate once further mRNA depletion began. Therefore, we quantitated L3 mRNA by measuring in vivo its rate of transcription and steady-state level. When grown under inducing conditions, the rate of transcription of L3 in GTCM-B cells was actually eightfold higher than normal (Table 3), probably because the GALIO activation sequence is more efficient than the one from $T C M I$ which it replaced. More importantly, steady-state in vivo labeling measure-

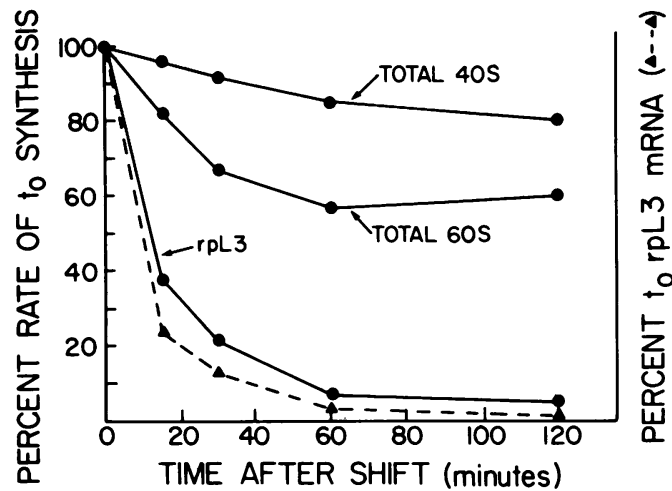

FIG. 2. Summary of in vivo measurements of ribosomal protein synthesis and in vitro mRNA quantitation. The solid lines show the relative rates of synthesis of the indicated ribosomal proteins at various times after GTCM-B cells were shifted from galactose $\left(\mathrm{t}_{0}\right)$ to glucose. Total $40 \mathrm{~S}$ and total $60 \mathrm{~S}$ are the average rates of synthesis for proteins of the small and large ribosomal subunits, respectively. Refer to Table 2 for rates of synthesis of the individual proteins. The dashed line shows the amount of L3 mRNA present relative to the preshift conditions, as quantitated from densitometric scans of blot hybridization analyses such as that shown in Fig. 1. 
TABLE 2. Relative rates of synthesis of ribosomal proteins ${ }^{a}$

\begin{tabular}{|c|c|c|c|c|c|c|c|}
\hline \multirow{3}{*}{ Protein } & \multicolumn{7}{|c|}{ Rate of synthesis at time postshift (min) after cessation of: } \\
\hline & \multicolumn{5}{|c|}{ L3 transcription (GTCM-B) } & \multicolumn{2}{|c|}{$\begin{array}{l}\text { L29 transcription } \\
\text { (GCYH-A) }\end{array}$} \\
\hline & $\mathbf{0}$ & 15 & 30 & 60 & 120 & 60 & 120 \\
\hline \multicolumn{8}{|l|}{$60 \mathrm{~S}$} \\
\hline $\mathbf{L}^{b}$ & 1.13 & 0.38 & 0.22 & 0.07 & 0.04 & 0.45 & 0.49 \\
\hline $\mathbf{L}^{b}$ & 0.96 & 0.63 & 0.33 & 0.27 & 0.27 & 0.51 & 0.63 \\
\hline rp3 & 1.07 & 0.79 & 0.83 & 0.81 & 0.81 & 0.82 & 0.90 \\
\hline L4 & 1.10 & 0.83 & 0.73 & 0.60 & 0.61 & 0.66 & 0.54 \\
\hline $\mathbf{L S}^{b}$ & 0.89 & 0.64 & 0.40 & 0.31 & 0.30 & 0.57 & 0.56 \\
\hline rp10 & 1.28 & 1.07 & 0.97 & 0.90 & 0.89 & 0.92 & 0.78 \\
\hline L6 & 1.07 & 0.86 & 0.73 & 0.60 & 0.69 & 0.81 & 0.76 \\
\hline $\mathrm{L}^{1} 3^{b}$ & 0.88 & 0.64 & 0.44 & 0.32 & 0.37 & 0.56 & 0.59 \\
\hline L10 & 1.02 & 0.85 & 0.61 & 0.58 & 0.58 & 0.67 & 0.63 \\
\hline L21 & 1.00 & 0.79 & 0.62 & 0.55 & 0.62 & 0.75 & 0.82 \\
\hline rp24 & 1.08 & 0.90 & 0.79 & 0.58 & 0.67 & 0.87 & 0.86 \\
\hline L30 & 0.86 & 0.80 & 0.65 & 0.56 & 0.54 & 0.78 & 0.69 \\
\hline rp38 & 1.04 & 0.97 & 0.80 & 0.63 & 0.68 & 0.79 & 0.83 \\
\hline L16 & 0.91 & 0.89 & 0.83 & 0.62 & 0.62 & 0.92 & 0.90 \\
\hline L29 & 0.67 & 0.67 & 0.58 & 0.46 & 0.43 & 0.49 & 0.51 \\
\hline rp57 & 1.23 & 0.84 & 0.83 & 0.72 & 0.81 & 0.95 & 0.76 \\
\hline \multicolumn{8}{|l|}{$40 S$} \\
\hline S7 & 1.28 & 1.18 & 1.02 & 0.93 & 0.99 & 0.87 & 0.94 \\
\hline S10 & 1.08 & 0.79 & 1.08 & 0.87 & 1.00 & 1.21 & 0.97 \\
\hline S4 & 0.86 & 0.93 & 0.85 & 0.79 & 0.70 & 0.86 & 0.62 \\
\hline S3 & 0.89 & 0.92 & 0.90 & 0.79 & 0.80 & 1.05 & 0.75 \\
\hline S2 & 1.16 & 0.93 & 0.88 & 0.82 & 0.89 & 1.40 & 1.19 \\
\hline S14/S15 & 0.95 & 0.96 & 0.91 & 0.77 & 0.75 & 0.78 & 0.70 \\
\hline S13 & 1.00 & 0.85 & 0.83 & 0.84 & 0.64 & 0.74 & 0.66 \\
\hline S12 & 1.14 & 1.10 & 0.90 & 0.78 & 0.82 & 0.94 & 0.82 \\
\hline S11 & 1.63 & 1.50 & 1.12 & 1.01 & 1.12 & 0.93 & 0.90 \\
\hline S18 & 1.03 & 0.97 & 0.97 & 0.87 & 0.76 & 0.80 & 0.75 \\
\hline S24 & 1.14 & 1.03 & 1.01 & 0.93 & 0.84 & 0.79 & 0.77 \\
\hline $\mathbf{S} 21$ & 1.00 & 0.80 & 0.79 & 0.93 & 0.91 & 0.77 & 0.66 \\
\hline S16 & 1.41 & 1.12 & 1.04 & 0.93 & 0.91 & 0.82 & 0.74 \\
\hline S27 & 1.13 & 0.97 & 0.84 & 0.72 & 0.74 & 0.77 & 0.74 \\
\hline rp51 & 1.42 & 1.24 & 1.20 & 1.09 & 0.94 & 0.89 & 1.10 \\
\hline
\end{tabular}

${ }^{a}$ Relative rates of synthesis of ribosomal proteins were measured as described in Materials and Methods. The values are the ${ }^{3} \mathrm{H} /{ }^{14} \mathrm{C}$ ratios of individual proteins normalized to the same ratio for total cell protein (see text). For strain GTCM-B, transcription of the L3 gene is dependent on the presence of galactose. For strain GCYH-A, the L29 gene is galactose dependent. Time zero refers to cells growing on galactose, and the other columns are elapsed time after the shift to glucose medium. For clarity, only the 60- and 120-min time points are shown for GCYH-A, as data for the others were essentially the same as for GTCM-B (except of course for L3 and L29).

b Significant change in synthesis rate occurred (see Results).

ments showed that L3 mRNA accumulated to about four times the usual level. As another steady-state measurement, densitometry of several blot hybridizations such as that in Fig. 1 showed that L3 mRNA was about twofold more abundant than in the wild type (data not shown). Thus, rather than there being too little L3 mRNA at the start of the experiment, L3 mRNA was actually in excess, so the failure to maintain synthesis of L3 during $\mathrm{mRNA}$ depletion could not be ascribed to an mRNA which was already being translated more efficiently.

Ribosomal protein synthesis in cells depleted of a single ribosomal protein. Since ribosomal proteins accumulate coordinately, it was of interest to examine their synthesis as synthesis of L3 diminished. Ribosomal protein L3 is a component of the $60 \mathrm{~S}$ subunit, and disappearance of this protein had essentially no effect on $40 \mathrm{~S}$ protein synthesis (Fig. 2). The picture for $60 \mathrm{~S}$ proteins was somewhat different (Table 2). For most of the proteins, there was a modest decline of about 20 to $40 \%$ in their rate of synthesis by $2 \mathrm{~h}$ after the shift. For a few proteins, however, such as L2, L5, and L13, there was a greater effect; their rates of synthesis fell by 60 to $70 \%$ within $2 \mathrm{~h}$. These measurements of large-subunit protein synthesis may have been influenced by rapid degradation of proteins no longer being assembled in the absence of L3 (see below). However, as discussed in detail later, the drop in synthesis of some proteins was too great to be accounted for simply by turnover. Rather, synthesis of some proteins may be specifically diminished when they cannot be assembled.

Like L3, the mRNA for ribosomal protein L29 has also been found to be translated with reduced efficiency when present in a relative excess (28). Thus, we were interested in the translational properties of L29 mRNA in conditions of reduced abundance. We constructed strain GCYH-A, in which transcription of the L29 gene was made inducer dependent (6). Strain GCYH-A was identical to strain 


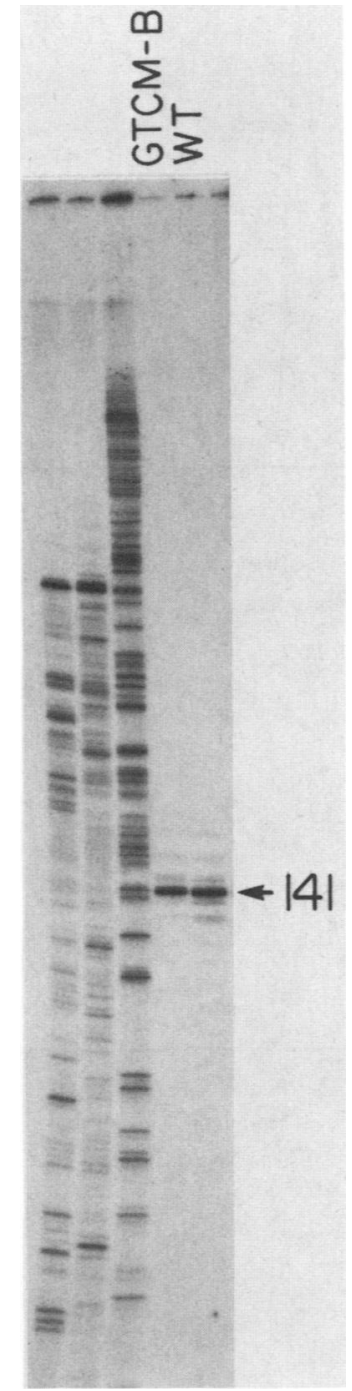

FIG. 3. Primer extension analysis of RNA derived from wildtype (WT) and GTCM-B cells. Cells were grown in galactosecontaining medium, and RNA was prepared. Total cellular RNA was hybridized to a synthetic DNA oligomer complementary to the L3 coding sequence, and the oligomer was extended on the L3 template with reverse transcriptase. The extended products of 141 nucleotides are shown in the rightmost two lanes. The other lanes contain dideoxy sequencing ladders as size markers.

GTCM-B in the disappearance of mRNA, growth rate before and after the shift from galactose to glucose medium, and total incorporation of $\left[{ }^{3} \mathrm{H}\right]$ leucine (data not shown). Unfortunately, we could not obtain reliable data for the rate of synthesis of L29. In a typical two-dimensional electrophoretic separation, this protein was poorly resolved, and even when L29 mRNA was completely undetectable, substantial radioactivity was still present in the L29 position of our gels. (There is evidence that the L29 spot is composed of two proteins [22].) Nevertheless, as far as other ribosomal proteins are concerned, cessation of L29 mRNA synthesis had an effect similar to that of a drop in synthesis of ribosomal protein L3. Ribosomal protein L29 is another 60S component, and $40 \mathrm{~S}$ proteins continued to be produced normally in the absence of transcription of L29 (Table 2). Moreover, the $60 \mathrm{~S}$ proteins displayed behavior similar to that in the previ- ous experiment; synthesis of those that were least affected by the absence of L 3 was likewise least affected by the absence of L29, while synthesis of L2, L5, and L13 was again reduced to a somewhat greater degree. Note that synthesis of L3 was also reduced about $50 \%$ by the absence of L29. We will return to this point later.

Analysis of ribosome accumulation in GTCM-B cells. Since labeling of small-subunit proteins was unaffected but labeling of large-subunit proteins was reduced, we surmised that in the absence of L 3 or L29 40S subunits, but not 60 S subunits, might still be assembled. The lack of assembly could cause reduced labeling through rapid turnover of unassembled proteins or perhaps by some form of posttranscriptional inhibition of their synthesis. Thus, we measured the assembly of ribosomal subunits by measuring the accumulation of mature rRNAs, since these RNA species are very rapidly degraded when unable to enter ribosomes (25). GTCM-B cells growing on galactose were pulse-labeled for $5 \mathrm{~min}$ with $\mathrm{L}-\left[\right.$ methyl $\left.-{ }^{3} \mathrm{H}\right]$ methionine to reveal initial synthesis of the precursor rRNA species and then chased for $15 \mathrm{~min}$ with unlabeled methionine to examine the accumulation of mature $18 \mathrm{~S}$ and $25 \mathrm{~S}$ rRNAs. The cells were then transferred to glucose and 1 and 2 hours later were submitted to the same pulse-chase regimen. RNA was extracted and separated by size in acrylamide gels. After transfer to glucose and cessation of L3 synthesis, rRNA was still being synthesized since $35 \mathrm{~S}$ precursor RNA was readily detected (Fig. 4). This RNA appeared to be processed as well, since at $1 \mathrm{~h}$ after the shift, $27 \mathrm{~S}$ and $20 \mathrm{~S}$ rRNA species were detected in a short pulse. However, after a 15-min chase, accumulation of mature $25 \mathrm{~S}$ rRNA was substantially reduced after transfer to glucose at the same time $18 \mathrm{~S}$ rRNA accumulated. Thus, in the absence of L3, 60S ribosomal subunits were not assembled, whereas assembly of the $40 \mathrm{~S}$ subunit was unaffected, at least up to 2 $\mathrm{h}$ after cessation of transcription of TCMI. Exactly the same results were found for strain GCYH-A, in which the L29 gene is galactose dependent (data not shown).

Evidence for reduced ribosomal protein synthesis. Having established that the $60 \mathrm{~S}$ subunit was not assembled without

TABLE 3. Relative rate of transcription and accumulation of various mRNAs in wild-type and GTCM-B cells ${ }^{a}$

\begin{tabular}{|c|c|c|c|c|}
\hline \multirow{3}{*}{$\begin{array}{l}\text { mRNA or } \\
\quad \text { ratio }\end{array}$} & \multicolumn{4}{|c|}{$\%$ of input cpm hybridized $\left(\times 10^{-3}\right)$ or relative rate ${ }^{b, c}$} \\
\hline & \multicolumn{2}{|c|}{ Wild type } & \multicolumn{2}{|c|}{ GTCM-B } \\
\hline & $\begin{array}{l}\text { 7-min } \\
\text { label }\end{array}$ & $\begin{array}{c}50-\text { min } \\
\text { label }\end{array}$ & $\begin{array}{l}\text { 7-min } \\
\text { label }\end{array}$ & $\begin{array}{c}50-\text { min } \\
\text { label }\end{array}$ \\
\hline Actin & 7.66 & 6.15 & 5.53 & 9.40 \\
\hline L29 & 14.90 & 4.00 & 8.62 & 6.72 \\
\hline L3 & 15.05 & 7.48 & 75.90 & 45.45 \\
\hline $\mathrm{L} 3 / \mathrm{L}^{2} 9^{b}$ & 1.01 & 1.87 & 8.81 & 6.76 \\
\hline L3/actin ${ }^{b}$ & 1.96 & 1.22 & 13.73 & 4.83 \\
\hline $\mathrm{L} 3 / \mathrm{L} 29^{c}$ & 1 & 1 & 8.72 & 3.61 \\
\hline L3/actin ${ }^{c}$ & 1 & 1 & 7.00 & 3.95 \\
\hline
\end{tabular}

${ }^{a}$ The rate of transcription of actin, L29, and L3 mRNAs was measured in wild-type cells and strain GTCM-B, in which the L3 gene requires galactose for transcription. Both strains were grown on galactose and labeled for 7 and 50 min with $\left[{ }^{3} \mathrm{H}\right]$ uracil, and the resulting $\left[{ }^{3} \mathrm{H}\right]$ RNA was hybridized to immobilized M13 phage clones of each gene (see Materials and Methods). Al hybridizations also included a filter containing M13 DNA, and the radioactivity remaining on this filter was subtracted as background from the others (usually about $10 \%$ of the counts per minute bound to other filters). Input counts per minute: $3 \times 10^{7}(7 \mathrm{~min}) ; 3 \times 10^{8}(50 \mathrm{~min})$.

${ }^{b}$ Data for L3 normalized to those for L29 or actin in the same column.

${ }^{c}$ Data from previous pairs (marked $b$ ) normalized to the wild type. 

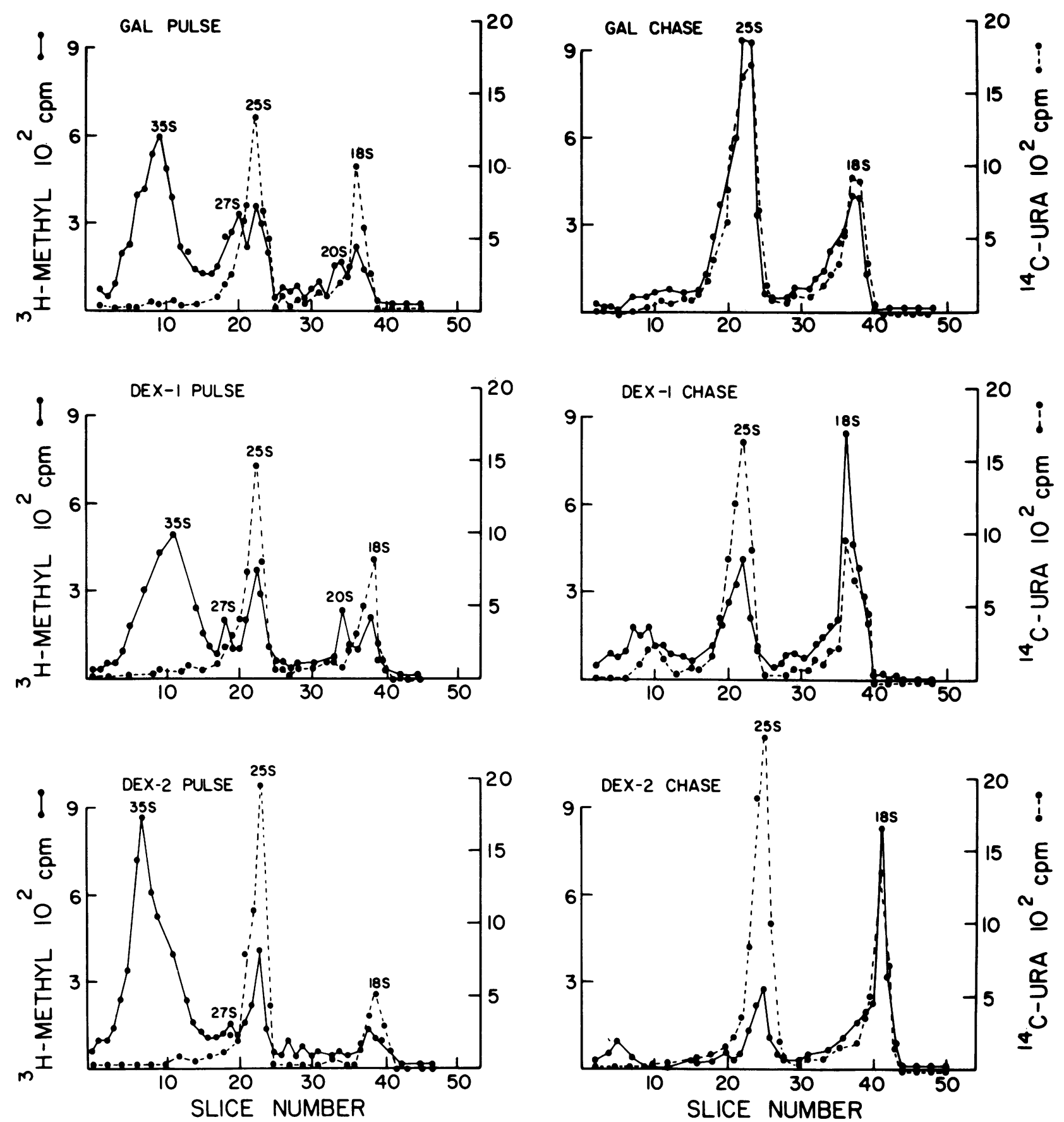

FIG. 4. Polyacrylamide gel analysis of ribosomal RNA synthesis and accumulation in GTCM-B cells. Cells growing on galactose were pulse-labeled for 5 min with $\mathrm{L}-\left[\right.$ methyl $\left.{ }^{-3} \mathrm{H}\right]$ methionine, and the culture was divided. Half was mixed with cells labeled for two generations with $\left[{ }^{14} \mathrm{C}\right]$ uracil and harvested (GAL PULSE). The other half was incubated with unlabeled methionine for $15 \mathrm{~min}$, mixed with ${ }^{14} \mathrm{C}$-labeled cells, and harvested (GAL CHASE). A portion of the original GTCM-B culture was then harvested and suspended in glucose-containing medium. After 1 and $2 \mathrm{~h}$ in glucose, samples of cells were also pulse-labeled and chased (DEX PULSE and DEX CHASE). Total RNA was extracted and separated in polyacrylamide tube gels, which were sliced and counted in a scintillation counter. Solid lines show the profile of ${ }^{3} \mathrm{H}$ and broken lines show the profile of ${ }^{14} \mathrm{C}$ in the gels.

L3 or L29, we speculated that the apparent reduction in synthesis of other $60 \mathrm{~S}$ proteins might be a regulatory response to limit the synthesis of these proteins. This response could be due to regulation at the level of transcription or translation. However, we have not ruled out the possibility that our measurements reflected rapid turnover of unassembled proteins rather than an actual decline in synthesis.
Although cloned genes for most of the affected proteins are unavailable, precluding direct examination of their expression, we pointed out that in the experiment in which synthesis of L29 was prevented there was a significant drop in labeling of $\mathrm{L} 3$ with $\left[{ }^{3} \mathrm{H}\right]$ leucine in a short pulse (Table 2). As we show below, for L3 at least, it is clear that this reduced labeling was due to an actual lower rate of synthesis. 


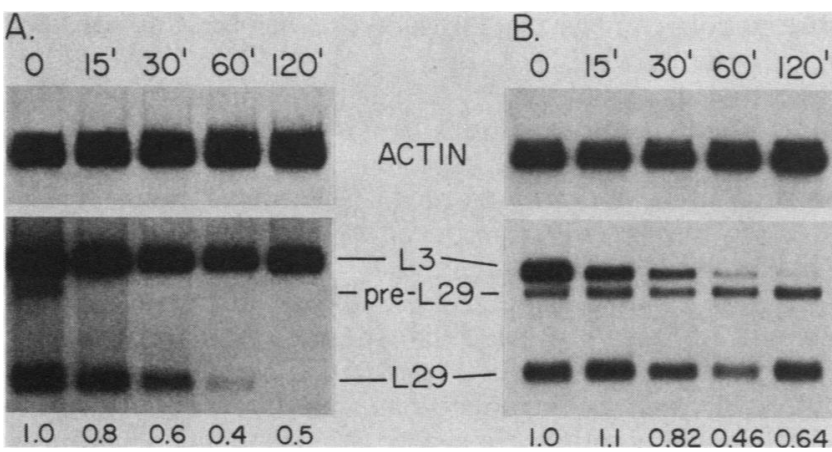

FIG. 5. Northern blot hybridization of RNA from strains GCYHA and GTCM-B. (A) Strain GCYH-A, in which the L29 gene is galactose dependent, was grown on galactose and shifted to glucose. Before the shift and at the indicated times thereafter, RNA was extracted from cells, electrophoresed, blotted, and hybridized. The lower part of the figure is a blot hybridized simultaneously to L3 and L29 DNA probes. The upper part of the figure is an identical blot hybridized to an actin gene probe. Several exposures of the autoradiographs were made, and the intensity of bands was measured by densitometry. The numbers at the bottom of the figure represent the intensity of the L3 signal relative to that of actin, each normalized to the galactose-grown RNA sample (time 0). (B) Strain GTCM-B, in which the L3 gene is galactose dependent, was grown on galactose and shifted to glucose. RNA was extracted and hybridized as in panel $A$. The numbers below this figure represent the intensity of the L29 signal relative to actin, each normalized to the galactose-grown sample.

Figure 5 shows blot hybridization analysis of RNA derived from GCYH-A cells grown on galactose and at various times after transfer to glucose. The disappearance of L29 mRNA can be seen clearly. In addition there was a definite diminution of L3 mRNA levels. Compared to the actin transcript, L3 mRNA was about one-half as prevalent at 1 or $2 \mathrm{~h}$ after cessation of L29 transcription as before the shift. While the reduction was not dramatic, it was quite reproducible, as the same result was obtained in three separate experiments. Furthermore, in wild-type cells L3 mRNA abundance did not change after a shift in carbon sources (data not shown).

To determine the cause for the diminished prevalence of L3 mRNA, we measured in vivo the rate of transcription and steady-state accumulation of L3, L29, and actin mRNAs. Transcription rate was determined by pulse-labeling cells with $\left[{ }^{3} \mathrm{H}\right]$ uracil before and after shifting GCYH-A cells to glucose medium and hybridizing the RNA to immobilized clones of the three genes. The results (Table 4) showed that, relative to the actin gene, the rate of transcription of $\mathrm{L} 3$ was essentially unchanged or perhaps even increased slightly. On the other hand, a long-term in vivo label confirmed the conclusion obtained by blot hybridization, i.e., that the steady-state level of L3 mRNA was only $50 \%$ of its preshift level by $2 \mathrm{~h}$ after the shift. Since transcription of L3 did not change but its steady-state accumulation was lower than usual, the stability of L3 mRNA must have been reduced under conditions in which ribosomal protein L29 was not synthesized.

In conclusion, these results showed that the $50 \%$ reduction in labeling of L3 observed in cells deprived of L29 could be accounted for completely by the lower abundance of L3 mRNA, leading to reduced synthesis of this protein, without invoking explanations of rapid turnover of unassembled protein. Interestingly, this phenomenon was not peculiar to L3. In a complementary experiment, when cells were de- prived of L3 (in GTCM-B), the abundance of L29 mRNA fell by about $50 \%$ (Fig. 5). The significance of the increased instability of L3 and L29 mRNAs is discussed below.

\section{DISCUSSION}

The ribosome is a complex organelle which depends on the interaction of at least 70 to 80 macromolecules to function. Despite its biochemical complexity, however, the ribosome constitutes an ideal system for genetic exploitation to reveal the mechanisms orchestrating the synthesis of numerous gene products in precise amounts relative to one another. Recently, several groups have used elevated gene dosage as one manipulation to identify regulatory features of $S$. cerevisiae ribosomal protein genes. Pearson and coworkers found that increasing the copy number of TCMI produced higher levels of L3 mRNA without increased synthesis of $\mathrm{L} 3$, suggesting translational regulation as a means to maintain the appropriate level of L3 (23). Warner et al. extended this type of analysis to six other ribosomal protein genes (28). One, $\mathrm{CYH} 2$, which encodes ribosomal protein $\mathbf{L} 29$, exhibited the same translational regulation as TCMI. On the other hand, genes for three other proteins did not appear to be regulated at the level of translation, as additional copies of them led to significantly higher rates of synthesis of their respective proteins. The excess protein was nevertheless degraded rapidly. In addition, $C Y H 2$ and the gene encoding rp73 may be regulated at the level of mRNA splicing, as their elevated copy number produced a large accumulation of precursor transcripts. Finally, apparent translational control of the genes encoding rp59 and rp39 (12; J. Woolford, personal communication) has also been observed in analogous gene dosage experiments. Thus, for excess mRNA, several mechanisms ensure stoichiometric production of each ribosomal protein.

In the present study we wished to determine the consequences of reducing the available mRNA for a single ribosomal protein. There were several reasons for this approach. First, increased gene dosage experiments concern synthesis of only one protein; in no case has the increased number of one ribosomal protein gene affected expression of any other gene. On the contrary, by reducing the amount of mRNA for

TABLE 4. Relative rate of transcription and accumulation of various mRNAs in strain GCYH-A

\begin{tabular}{|c|c|c|c|c|c|c|}
\hline \multirow{3}{*}{$\begin{array}{l}\text { mRNA } \\
\text { or ratio }\end{array}$} & \multicolumn{6}{|c|}{$\%$ of input cpm hybridized $\left(\times 10^{-3}\right)$ or relative rate $e^{c, d}$} \\
\hline & \multicolumn{2}{|c|}{$0 \mathrm{~h}$} & \multicolumn{2}{|c|}{$1 \mathrm{~h}$} & \multicolumn{2}{|c|}{$2 \mathrm{~h}$} \\
\hline & $\begin{array}{l}\text { 7-min } \\
\text { label }\end{array}$ & $\begin{array}{c}\text { 50-min } \\
\text { label }\end{array}$ & $\begin{array}{l}\text { 7-min } \\
\text { label }\end{array}$ & $\begin{array}{c}50-\text { min } \\
\text { label }\end{array}$ & $\begin{array}{l}\text { 7-min } \\
\text { label }\end{array}$ & $\begin{array}{c}\text { 50-min } \\
\text { label }\end{array}$ \\
\hline Actin & 4.74 & 5.37 & 2.85 & 4.93 & 3.45 & 5.74 \\
\hline L29 & 13.60 & 6.45 & $\mathrm{ND}^{b}$ & ND & ND & ND \\
\hline L3 & 8.42 & 7.11 & 4.44 & 4.16 & 7.92 & 4.40 \\
\hline L3/actin ${ }^{c}$ & 1.78 & 1.32 & 1.56 & 0.84 & 2.30 & 0.77 \\
\hline L3/actin ${ }^{d}$ & 1 & 1 & 0.88 & 0.64 & 1.29 & 0.58 \\
\hline
\end{tabular}

a The rate of transcription and steady-state accumulation of actin, L29, and L3 mRNAs in strain GCYH-A, in which the L29 gene requires galactose to be transcribed, were measured as described in the text. Cells were grown initially in galactose $(0 \mathrm{~h})$ and then transferred to glucose medium, and they were sampled 1 and $2 \mathrm{~h}$ later. The data are averages of two experiments. Input counts per minute: $3 \times 10^{6}(7 \mathrm{~min}) ; 10^{7}(50 \mathrm{~min})$.

${ }^{b}$ ND, Not detectable.

c Data for L3 normalized to data for actin in the same column.

${ }^{d}$ L3/actin ratios normalized to data for galactose-grown cells. 
a particular ribosomal protein, synthesis of all ribosomal proteins can be evaluated. Either translation of the affected mRNA must remain commensurate with the others, or if not, then all other ribosomal protein mRNAs will be in excess and factors which limit accumulation of the other proteins should be revealed.

Second, by examining the synthesis of a ribosomal protein whose mRNA was less prevalent, we expected to distinguish between possible types of translational control. As in E. coli, regulation might be due to repression of translation by an excess of unassembled ribosomal protein binding to its mRNA (21). Alternatively, the translation rate might be elevated, as well as inhibited, by a mechanism operating differently from classic repression. We had raised this possibility in a previous report describing $S$. cerevisiae strains in which the activity of the $T C M I$ promoter could be greatly reduced (6). Upon switching to conditions of reduced promoter activity, preexisting L3 mRNA appeared to decay more slowly. In addition, in steady state these cells accumulated more L3 mRNA than expected from measurements of the activity of the TCMI promoter fused to the $E$. coli $\beta$-galactosidase gene. We speculated that a lower than usual amount of L3 mRNA was stabilized against degradation by being translated more efficiently. Enhanced translation of ribosomal protein mRNAs has been suggested in other contexts as well. Kim and Warner (14) reported from in vivo labeling measurements that the efficiency of utilization of several yeast ribosomal protein mRNAs, among them $\mathrm{L} 3$, is only 20 to $50 \%$ during normal growth, leading these investigators to suggest the possible existence of a reserve of translational potential which might be used to increase ribosome synthesis rapidly, as occurs during nutritional upshift (13). Also, Geyer et al. presented evidence that the rate of ribosomal protein synthesis may be regulated in growth-stimulated mouse cells by a specific increase in the efficiency of translation of ribosomal protein mRNAs (8).

In this report, the synthesis of ribosomal protein L3 was measured over a 20-fold range in abundance of its mRNA. By using a strain with a conditionally transcribed gene, we circumvented the necessity of examining cells already adjusted to altered gene activity or number. In addition, since the translation rate of any mRNA depends on the number of available ribosomes, the activity of an underrepresented ribosomal protein mRNA should be measured when there is no change in the ribosome content of the cells. Such a change would occur if the particular ribosomal protein became limiting in ribosome assembly due to there being less of its mRNA. This problem was also avoided by using a conditionally expressed gene.

After cessation of L3 transcription and progressive depletion of its mRNA, at no point did there appear to be more efficient translation of the mRNA. Lack of enhanced translation was not due to a different sequence of the mRNA derived from the transcriptionally modified L3 gene, as primer extension analysis showed the $5^{\prime}$ sequence to be identical to the wild type sequence. The results also were not because the cells had already exhausted their capacity for elevating translation of $\mathrm{L} 3$, since $\mathrm{L} 3$ mRNA was not present in a limiting amount prior to cessation of transcription. In fact, the mRNA was two to four times more prevalent than normal. Since the half-life of L3 mRNA is usually about 10 to $15 \mathrm{~min}$ (14) and there was at least twice as much of this transcript before its further transcription was eliminated, we should have seen at least a 10- to 15 -min lag before any decline in L3 synthesis. However, by 15 min after the shift, L3 synthesis was diminished by $60 \%$. While unexpected, this observation emphasizes the fact that translation was not made more efficient.

Bearing in mind that the actual transcription rate of L3 under noninducing conditions could be higher than thought, how might these results be reconciled with our previous suggestion that less mRNA might be more efficiently translated? In the present experiment we examined in effect the translation of a preexisting and (initially) underutilized mRNA population as that mRNA was progressively depleted. The results showed that the preexisting mRNA did not become more efficiently translated. However, at steady state over many cell generations, greatly reduced growth rate, and with continued although greatly reduced synthesis of mRNA, perhaps that mRNA is eventually stabilized by more efficient utilization to produce a larger than expected accumulation. Nonetheless, we also reported that preexisting L3 mRNA decayed progressively more slowly after a shift to noninducing conditions (6), a result indicating immediate stabilization. Since its abundance was measured relative to that of another ribosomal protein transcript (L29), we repeated L3 mRNA quantitation with actin as a control (Fig. 1); the result was essentially the same, an apparent slowing in mRNA turnover (data not shown). While we cannot suggest a definitive explanation for this observation, the fact remains that at whatever rate L3 mRNA was depleted, L3 synthesis did not remain equal to that of the other ribosomal proteins even for a short time. Again, this result is made more definitive by the fact that the mRNA was in excess from the start.

The situation presented above highlights an important aspect of ribosomal protein gene regulation in eucaryotes. Our results imply that translation of a ribosomal protein mRNA is not immediately sensitive to a deficiency or possibly even an excess of its corresponding protein in the nucleus (ribosome assembly takes place in the nucleus) once that mRNA appears in the cytoplasm. Ribosomal proteins enter the nucleus regardless of their ability to be assembled $(3,26)$. Any excess protein which could not be assembled might lead to an event which adjusts the translational efficiency of its mRNA. The mRNA would leave the nucleus destined for a given translational efficiency based on information about the state of assembly imparted in the nucleus. Thus, if increased translatability were later required, only new mRNA could be employed. Clearly, more direct evidence for these proposals is necessary, such as examining the translation of excess mRNA encoding a form of protein L3 unable to be transported into the nucleus.

Given that L3 synthesis was not maintained, it was of interest to quantitate the synthesis of other ribosomal proteins. In the absence of $\mathrm{L} 3,40 \mathrm{~S}$ proteins were produced continuously and pulse-chase measurements showed that $40 \mathrm{~S}$ subunits were accumulated. This observation was not surprising, since L 3 is a $60 \mathrm{~S}$ protein and there are many examples in which one subunit is accumulated over the other because of defects in assembly $(1,2,19)$.

Without L3, 60S subunits did not accumulate and synthesis of most $60 \mathrm{~S}$ proteins dropped an average of $40 \%$. Several proteins such as L2, L5, and L13 showed a more substantial reduction of 60 to $70 \%$. Possibly the decrease in labeling of most proteins was actually due to their rapid degradation in the absence of assembly. However, we suggest that rapid turnover does not account fully for the greater reduction in synthesis of a subset of $60 \mathrm{~S}$ proteins. In a 3-min pulse, the unassembled half-life of these proteins would have to be less than $1 \mathrm{~min}$ if turnover alone were responsible for the observed labeling. The half-life of $60 \mathrm{~S}$ ribosomal proteins 
synthesized in the absence of rRNA was measured previously at 7 to $20 \mathrm{~min}$ (11). In that experiment proteins L2, L5, and L13 (designated rp2, rp8, and rp15 in reference 11) had half-lives of 24,8 , and $13 \mathrm{~min}$, respectively. In a gene dosage experiment, excess ribosomal protein $\mathrm{S} 10$ decayed with a 5-min half-life (28). Thus, our measurements should have reflected initial synthesis. While this may be circumstantial support, more compelling was the observation that in the absence of L29 the abundance of L3 mRNA dropped by $50 \%$, so for this protein at least, reduced labeling can be accounted for completely by diminished synthesis from less mRNA rather than by rapid degradation. An attempt is under way to isolate the genes for L5 and L13 to determine whether the same explanation applies to these proteins.

We have not further determined why reduced synthesis of L29 leads to a reduction in L 3 mRNA or vice versa. Previous work has shown that translation of L3 or L29 mRNA is diminished when these transcripts are in excess, and reduced translation was coincident with a shorter half-life of these mRNAs $(23,28)$. In the present case the failure of an entire subunit to be assembled would leave excess L3, just as in the former situation too much mRNA might produce more L3 than could be assembled. Again, for L3 we observed a shortened mRNA half-life. Perhaps this effect could be due to reduced translation. However, it must be pointed out that in the previous work, even though excess L3 or L29 mRNAs were more unstable, there was nevertheless a threeto fivefold increase in translatable mRNA at steady state yet no increase in synthesis of the corresponding proteins. In the present case, if lack of assembly leads to reduced translation of L3, a greater reduction in translation should have been observed if the same mechanism were at work. Instead, we found a one-to-one correspondence between L3 mRNA abundance and synthesis of L3. In the former case, in which L3 mRNA was overproduced, the transcript was found in smaller polyribosomes, confirming that it was being undertranslated (28). Polysome analysis for L3 mRNA as well as for proteins such as L2, L5, and L13 will be necessary to determine whether lack of assembly leads to reduced translation of a subset of ribosomal protein mRNAs. In any event, it is interesting that proteins L2, L3, L5, L13, and L29, all of which may regulate their synthesis through assembly, are presumed to be among the first proteins which assemble with rRNA, as Lee and co-workers found that they are the most resistant to removal from $60 \mathrm{~S}$ subunits by high-salt extraction (17). Indeed, L29 binds directly to $5.8 \mathrm{~S}$ rRNA (18), and L2, L3, and L5 have been found to crosslink to $25 S$ rRNA with 2-iminothiolane (4). If posttranscriptional regulatory mechanisms such as reduced translation do operate, proteins which are assembled first might be more stringently regulated, since controlling ribosome assembly at an early step would prevent unnecessary accumulation immediately.

\section{ACKNOWLEDGMENTS}

This work was supported by National Science Foundation grant PCM-8215576 and by American Cancer Society institutional grant IN-15X.

We thank John Abelson for providing the actin clone, Dana Fowlkes for synthesizing the DNA oligomer, Mark Underwood for help with primer extension analysis, and Steve Loechel for expert technical assistance. We also thank John Lee for communicating results prior to publication.

\section{LITERATURE CITED}

1. Andrew, C., A. K. Hopper, and B. D. Hall. 1976. A yeast mutant defective in processing of 27S rRNA precursor. Mol. Gen.
Genet. 144:29-37.

2. Bayliss, F. T., and J. L. Ingraham. 1974. Mutation in Saccharomyces cerevisiae conferring streptomycin and cold sensitivity by affecting ribosome formation and function. J. Bacteriol. 118:319-328.

3. Darmer, D., H. Kalthoff, and D. Richter. 1984. Subcellular distribution of ribosomal proteins S6 and L12. Analysis by autoradiography and immunofluorescence of sections from oocytes of Xenopus laevis. Cell Tissue Res. 237:353-356.

4. El-Baradi, T. T. A. L., H. A. Raué, M. Linnekamp, and R. J. Planta. 1985. Identification of yeast $60 \mathrm{~S}$ ribosomal proteins crosslinked to rRNA by 2-iminothiolane. FEBS Lett. 186:26-30.

5. Elion, E. A., and J. R. Warner. 1984. The major promoter element of rRNA transcription in yeast lies $2 \mathrm{~KB}$ upstream. Cell 39:663-673.

6. Fried, H. M., H. G. Nam, S. Loechel, and J. Teem. 1985. Characterization of yeast strains with conditionally expressed variants of ribosomal protein genes $t \mathrm{cml}$ and $c y h 2$. Mol. Cell. Biol. 5:99-108.

7. Fried, H. M., and J. R. Warner. 1981. Cloning of the yeast gene for trichodermin resistance and ribosomal protein L3. Proc. Natl. Acad. Sci. USA 78:238-242.

8. Geyer, P. K., O. Meyuhas, R. P. Perry, and L. F. Johnson. 1982. Regulation of ribosomal protein mRNA content and translation in growth-stimulated mouse fibroblasts. Mol. Cell. Biol. 2:685-693.

9. Gold, L., D. Pribnow, T. Schneider, S. Shinedling, B. Singer, and G. Stormo. 1981. Translational initiation in prokaryotes. Annu. Rev. Microbiol. 35:365-403.

10. Gorenstein, C., and J. R. Warner. 1976. Coordinate regulation of the synthesis of eukaryotic ribosomal proteins. Proc. Natl. Acad. Sci. USA 73:1547-1551.

11. Gorenstein, C., and J. R. Warner. 1977. Synthesis and turnover of ribosomal proteins in the absence of $60 \mathrm{~S}$ subunit assembly in Saccharomyces cerevisiae. Mol. Gen. Genet. 157:327-332.

12. Himmelfarb, H. J., A. Vassarotti, and J. D. Friesen. 1984. Molecular cloning and biosynthetic regulation of the cryl gene of Saccharomyces cerevisiae. Mol. Gen. Genet. 195:500-506.

13. Kief, D. R., and J. R. Warner. 1981. Coordinate control of synthesis of ribosomal ribonucleic acid and ribosomal proteins during nutritional shift-up in Saccharomyces cerevisiae. Mol. Cell. Biol. 1:1007-1015.

14. Kim, C. H., and J. R. Warner. 1983. Messenger RNA for ribosomal proteins in yeast. J. Mol. Biol. 165:79-89.

15. Kozak, M. 1980. Influence of mRNA secondary structure on binding and migration of 40S ribosomal subunits. Cell 19:79-90.

16. Kruiswijk, T., and R. Planta. 1974. Analysis of the protein composition of yeast ribosomal subunits by two-dimensional acrylamide gel electrophoresis. Mol. Biol. Rep. 1:409-415.

17. Lee, J. C., R. Anderson, Y. Yeh, and P. Horowitz. 1985. Extraction of proteins from Saccharomyces cerevisiae ribosomes under nondenaturing conditions. Arch. Biochem. Biophys. 237:292-299.

18. Lee, J. C., B. Henry, and Y. Yeh. 1983. Binding of proteins from the large ribosomal subunits to 5.8S rRNA of Saccharomyces cerevisiae. J. Biol. Chem. 258:854-858.

19. Loo, M. W., N. S. Schricker, and P. J. Russell. 1981. Heatsensitive mutant strain of Neurospora crassa, $4 \mathrm{M}(\mathrm{t})$, conditionally defective in $25 \mathrm{~S}$ rRNA production. Mol. Cell. Biol. 1:199-207.

20. McGarry, T. J., and S. Lindquist. 1985. The preferential translation of Drosophila HSP70 mRNA requires sequences in the untranslated leader. Cell 42:903-911.

21. Nomura, M., R. Gourse, and G. Baughman. 1984. Regulation of the synthesis of ribosomes and ribosomal components. Annu. Rev. Biochem. 53:75-117.

22. Otaka, E., and S. Osawa. 1981. Yeast ribosomal proteins: correlation of several nomenclatures and proposal of a standard nomenclature. Mol. Gen. Genet. 181:176-182.

23. Pearson, N. J., H. M. Fried, and J. R. Warner. 1982. Yeast use translational control to compensate for extra copies of a ribosomal protein gene. Cell 29:347-355.

24. Pelletier, J., and N. Sonenberg. 1985. Insertion mutagenesis to 
increase secondary structure within the $5^{\prime}$ noncoding region of eukaryotic mRNA reduces translational efficiency. Cell 40:515-526.

25. Shulman, R. W., and J. R. Warner. 1978. Ribosomal RNA transcription in a mutant of $S$. cerevisiae defective in ribosomal protein synthesis. Mol. Gen. Genet. 161:221-223.

26. Warner, J. R. 1979. Distribution of newly formed ribosomal proteins in HeLa cell fractions. J. Cell Biol. 80:767-772.

27. Warner, J. R. 1982. The yeast ribosome: structure, function, and synthesis, p. 529-560. In J. N. Strathern, E. W. Jones, and J. R. Broach (ed.), The molecular biology of the yeast Saccharomyces. Cold Spring Harbor Laboratory, Cold Spring Harbor, N.Y.

28. Warner, J. R., G. Mitra, W. F. Schwindinger, M. Studeny, and H. M. Fried. 1985. Saccharomyces cerevisiae coordinates the accumulation of yeast ribosomal proteins by modulating mRNA splicing, translational initiation, and protein turnover. Mol. Cell. Biol. 5:1512-1521. 